\title{
TLR4/NF-KB SIGNALING PATHWAY IS A KEY PATHOGENIC EVENT OF LUNG INJURY IN BLEOMYCIN-INDUCED PULMONARY FIBROSIS IN A MOUSE MODEL
}

\author{
Mostafa Sabry ${ }^{1 *}$, Hesham H. Taha ${ }^{1}$, Amany Osama Mohamed ${ }^{2}$, Khaled Thabet ${ }^{3}$, Ali A. \\ Hasan $^{4}$, Abdel-Razik H. Abdel-Razik ${ }^{5}$ and Bakheet E. M. Elsadek ${ }^{1}$ \\ ${ }^{1}$ Department of Biochemistry, Faculty of Pharmacy, Al-Azhar University, Assiut, \\ Egypt. \\ ${ }^{2}$ Department of Biochemistry, Faculty of Medicine, Assiut University, Assiut, Egypt. \\ ${ }^{3}$ Department of Biochemistry, Faculty of Pharmacy, Minia University, Minia, Egypt. \\ ${ }^{4}$ Department of Chest Diseases, Faculty of Medicine, Assiut University, Assiut, Egypt. \\ ${ }^{5}$ Department of Histology, Faculty of Veterinary Medicine, Beni-Suef University, Beni- \\ Suef, Egypt.
}

*Corresponding author: mostafagaballah@azhar.edu.eg,

\begin{abstract}
Interstitial lung disease (ILD) comprises many chronic lung diseases with various degrees of inflammation and fibrosis. Idiopathic pulmonary fibrosis (IPF) is a specific lung disorder characterized by progressive fibrosis leading to end-stage lung disease, respiratory failure, and fatal outcome. The toll like receptor (TLR) family serves as an important regulatory role in the innate immune system. Recently, several studies implicated TLR signaling in the proinflammatory response of a variety of endogenous and exogenous stimuli within the lung. Innate immune activation via TLR4 contributes to lung injuries but its role in tissue remodeling during ILD is still unclear. The current study aimed to investigate role of lung TLR4, nuclear factor kappa B (NF$\mathrm{kB}$ ), transforming growth factor- $\beta$ (TGF- $\beta$ ) and interleukin $1 \mathrm{~B}$ (IL1B) in the pathogenesis of IPF. We examined the expression pattern of TLR4, NF-kB, TGF and IL1B after one and three weeks of bleomycin-induced pulmonary fibrosis in a mouse model. Expression of TLR4 and its downstream modulator NF-kB were markedly elevated. Consequently, expression of profibrogenic cytokine TGF- $\beta$ and inflammatory cytokines IL1B were induced in all grades of pulmonary fibrosis of mice model. Furthermore, there was an increase in interstitial collagen deposition side by side with induction of the activity of some pathophysiological enzymes and uric acid. In conclusion, our findings exhibit the importance of TLR4/NF-kB as significant mediators in fibrotic lung injury and open the door for future studies that can improve the lifestyle of IPF patients.
\end{abstract}

Keywords: TLR4; TGF- $\beta$; lung; bleomycin; fibrosis; IL1B; ILD; IPF; NF-kB. 


\section{Introduction}

Interstitial lung diseases (ILDs), a heterogeneous group of disorders characterized by inflammatory and fibrotic lung diseases with high morbidity and mortality, also defined as diffuse parenchymal lung disease(Ge et al., 2020). The most extensively studied type of ILD is idiopathic pulmonary fibrosis (IPF), which occurs mainly in adults aged over 60 years and is characterized by progressive pulmonary fibrosis, decline in lung function and high mortality(Kolb et al., 2019).

The model of bleomycin (BLM)-induced lung fibrosis represents the most commonly applied experimental model. BLM is a chemotherapeutic antibiotic that has been identified as a pro-fibrotic agent. A recent An Official American Thoracic Society Workshop Report confirmed that there is a consensus view of the intratracheal BLM model as "the best-characterized animal model available for preclinical testing"'(Tashiro et al., 2017).

Tissue damage and inflammation are important triggers for regeneration and fibrosis. Tissue damage not only induces inflammation in general, it also determines the type and polarization of inflammation by recruiting and activating a variety of different cells types of the innate and adaptive immune system(Mack, 2018).

The toll like receptors (TLRs) have crucial roles in activating the innate immune system, and at least 10 members of the TLR family have been identified in humans. These receptors are activated by several ligands and modulate inflammation. TLR4 is one of the TLRs that is expressed on the cell surface of both immune and vascular cells, smooth muscle cells, and inflammatory cells(Mitsui et al., 2020). It is amazing that the expression of TLR mRNA are not restricted to immune tissues but distributed in all tissues including lung(El-Zayat et al., 2019).

Nuclear factor kappa B (NF- $\kappa \mathrm{B})$ is a family of dimeric DNA binding transcription factors that modulate diverse biological responses to cellular stress by regulating the expression of hundreds of effector genes controlling these processes (Mulero et al., 2019). The TLR4 and NF- $\kappa B$ are involved in inflammation and apoptosis. The activation of TLR4 can induce the secretion of inflammatory cytokines, including interleukin 1B (IL1B) which are mediated by NF- $\kappa B$ (Luo et al., 2019).

The transforming growth factor- $\beta$ (TGF- $\beta$ ) signaling pathway plays a central role in the initiation and progression of tissue fibrosis(Jiang et al., 2019). Injury of alveolar epithelial cells results in activation of several pro-inflammatory, pro-coagulant, and pro-fibrotic mediators, of which TGF- $\beta 1$ is the most established. TGF- $\beta 1$ has been localized to areas of fibrosis in both experimental and human pulmonary fibrosis(Reed et al., 2019). TGF- $\beta 1$, a main profibrogenic cytokine in the progression of IPF, induces differentiation of pulmonary fibroblasts to myofibroblasts that produce high levels of collagen, leading to concomitantly loss of lung elasticity and function(Wei et al., 2019).

TLR4 enhances TGF- $\beta$ signaling and hepatic fibrosis(Seki et al., 2007), we sought to suggest the same pathway in lung and determine the expression of both pulmonary TLR4 and TGF- $\beta$ after one and three weeks of BLM, and explore the impact 
of TLR4 and its downstream regulator NF-kB expression on early and late lung injury by BLM in a mouse model.

\section{Materials and Methods}

\subsection{Animals and experimental design}

Fifteen male balb/c mice (age, 6-8 weeks; weight, 25-32 g) were purchased from the laboratory animal colony, Assiut University, Assiut, Egypt. Mice (5 per cage) were acclimated for one week at a regulated environment $\left(25^{\circ} \mathrm{C}, 12 \mathrm{~h}\right.$ light/dark cycle $)$ with free access to standard pellet diet and tap water. All animals received professional human care in compliance with International Ethical Guidelines for Animal Care (US Naval Medical Research Center, Unit No.3, Abbaseya, Cairo, Egypt) accredited by the Association for Assessment and Accreditation of Laboratory Animal Care International.

\subsection{BLM-Induced Pulmonary Fibrosis Mouse Model}

Subsequent to acclimatization, mice were randomly assigned into 3 groups as follow: one week group $(n=5)$, three weeks group $(n=5)$ and Sham-operated group $(n=5)$. The model was performed under intraperitoneally anesthesia with an anesthetic solution that contained $100 \mathrm{mg} / \mathrm{kg}$ ketamine and $10 \mathrm{mg} / \mathrm{kg}$ xylazine. The anesthetized animal was positioned supine on a dissection plate, heated by artificial lighting, and the neck skin was cleaned, shaved and disinfected with iodine alcohol. To induce pulmonary fibrosis, mice were treated with a single sublethal dose of BLM (Bleocel 15, Celon, India) $(3 \mathrm{mg} / \mathrm{kg})$ via intratracheal infusion in sterile isotonic saline $(50 \mu \mathrm{L}$ per animal) was intratracheally instilled by a $1 \mathrm{~mL}$ syringe to each animal at the start of the study (day 0)(Liu et al., 2017a; Liu et al., 2017b). The mice in sham control group were treated with an intratracheal instillation of equivalent saline.

After one or three weeks of model or sham operation, blood samples were collected from retro-orbital plexus for serum preparation and the mice were sacrificed by cervical decapitation under ketamine/xylazine anesthesia, autopsy was performed, and lung tissues were harvested and immediately washed with physiological saline. The excised lung was divided into 3 parts; one part was stored in 10\% neutral buffered formalin solution and subjected for histopathological examination. The other two parts were stored separately at $-80^{\circ} \mathrm{C}$ for subsequent biochemical and molecular assays.

\subsection{RNA Isolation and qRT-PCR:}

Total RNA was extracted from lung tissues using RNeasy Mini kit reagent (Qiagen, Germany) per manufacture instructions. RNA concentrations were determined spectrophotometrically by Nanodrop (Thermo Fisher Scientifics, Waltham, MA). Synthesis of double-stranded cDNA was achieved by using High Capacity cDNA Reverse Transcription kit (Qiagen, Germany) according to manufacture instructions. Produced cDNA was subjected to qPCR using a StepOnePlus ${ }^{\mathrm{TM}}$ Real-Time PCR system (Applied Biosystems, USA) with Maxima SYBR Green qPCR Master Mix (Qiagen, Germany) according to the standard protocol. A list of primers sequences is provided in table (1). 
Table (1): primer sequences for mice TLR4, NF-kB, IL1B, TGF- $\beta$ and house-keeping GAPDH used for qRT-PCR analysis of their mRNA expression in BLM-induced pulmonary fibrosis in mice.

\begin{tabular}{|c|c|}
\hline Primer & Sequence \\
\hline \multirow{2}{*}{ TLR4 (mouse) } & Forward:5-GGACTCTGATCATGGCACTG-3 \\
& Reverse:5-CTGATCCATGCATTGGTAGGT-3 \\
\hline NF-kB (mouse) & Forward:5-GCCTCTTCTCATTCCTGCTTG-3 \\
& Reverse:5-CTGATGAGAGGGAGGCCATT-3 \\
\hline IL1B (mouse) & Forward:5-AGTTGACGGACCCCAAAAG-3 \\
& Reverse:5-AGCTGGATGCTCTCATCAGG-3 \\
\hline TGF- $\beta$ (mouse) & $\begin{array}{r}\text { Forward:5-TGGAGCAACATGTGGAACTC-3 } \\
\text { Reverse:5-GTCAGCAGCCGGTTACCA-3 }\end{array}$ \\
\hline GAPDH (mouse) & $\begin{array}{r}\text { Forward:5-GGGTTCCTATAAATACGGACTGC-3 } \\
\text { Reverse:5-CCATTTTGTCTACGGGACGA-3 }\end{array}$ \\
\hline
\end{tabular}

2.4. Assessment the effect of BLM on pathophysiological markers in lung injury model

Serum uric acid was assayed by colorimetric procedure using a kit provided from Spinreact (Santa Coloma, Spain). Serum Creatine Kinase (CK) was assayed by kinetic procedure using a kit provided from Reactivos GPL (Barcelona, Spain). Serum Lactate Dehydrogenase (LDH) was assayed by kinetic procedure using a kit provided from Spectrum Diagnostic (Cairo, Egypt). Serum Gamma-glutamyl transferase (GGT) was assayed by kinetic procedure using a kit provided from Spectrum Diagnostic (Cairo, Egypt). Serum Alkaline Phosphatase (ALP) and serum Aspartate aminotransferase (AST) were assayed by kinetic procedure using a kit provided from Chema Diagnostic (Monsano, Italy).

\subsection{Histopathological examinations of lung tissue}

For histopathological examination, lung tissues were fixed in $10 \%$ neutral buffered formalin solution. Washing was carried out in sterile tap water, and then in serial dilutions of alcohols (methyl, ethyl and absolute ethyl) which were used for dehydration. Specimens were cleared in xylene and embedded in paraffin at $56{ }^{\circ} \mathrm{C}$ in a hot air oven for 24 hours. Paraffin bees wax tissue blocks were prepared for sectioning at 4 microns thickness by a sledge microtome and the obtained tissue sections were placed on glass slides, deparaffinized, stained by hematoxyline \& eosin (H\&E) stain and Masson's trichrome and then examined under light microscope (Olympus, USA) by a histopathologist who was blinded to the groups arrangement for assessment of histopathological changes(Page, 1983).

\subsection{Statistical analysis}

Statistical analyses of the data were carried out using GraphPad prism version 8.0 (Graph pad software San Diego, USA). Data comparisons were performed using 
analysis of variance (ANOVA) followed by Dunnett's test. The levels of significance were accepted with $p<0.05$ and all relevant results were graphically displayed as mean \pm SEM.

\section{Results}

\subsection{Histopathological assessment}

Lung tissue in control sham group showed normal pulmonary tissue containing normal bronchioles (B) and normal alveoli (A). Note, normal and thin inter-alveolar septum (arrow) with H\&E stain X100 as in figure1A. Masson's trichrome stain $\times 100$ of lung tissue in control sham group showed normal pulmonary tissue containing normal bronchioles and normal alveoli. Note, fine collagenic fibers between around the bronchioles and blood vessels as in figure $1 \mathrm{~B}$.

Lung tissue in one week treated group showed pulmonary tissue suffered from degenerative changes in the lining epithelium of bronchioles (B) and few alveoli (arrowhead) the others appeared normal (A). The inter-alveolar septum appeared thicker (arrow) with H\&E stain X100 as in figure 1C. Masson's trichrome stain $\times 100$ of lung tissue in one week treated group showed pulmonary tissue contained collagenic bundles around bronchioles (arrow) and penetrating between the alveoli in the inter-alveolar septum (arrowhead) as in figure 1D.

Lung tissue in three weeks treated group showed atlectatic pulmonary tissue containing a marked number of atrophied alveoli (A) and few emphysematous alveoli (E). Note, cellular infiltration (arrow) in the atlectatic tissue with H\&E stain X100 as in figure 1E. Masson's trichrome stain $\times 100$ of lung tissue in three weeks treated group showed pulmonary tissue compensated by proliferative collagenic bundles around bronchioles and the alveoli (arrow). Note, marked number of atrophied alveoli (A) and few emphysematous alveoli (E) as in figure $1 \mathrm{~F}$.

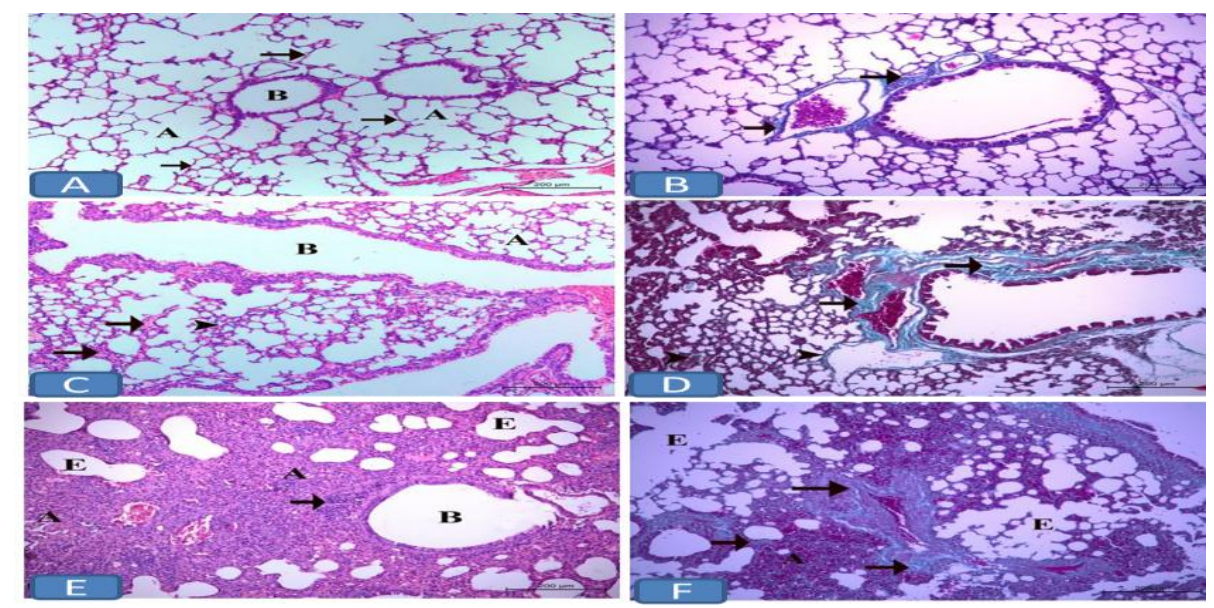

Figure 1: Histological analysis of BLM-induced lung injury after one and three weeks. Representative images of H\&E (A,C and E) and Masson's trichrome stain (B,D and F) $\mathrm{X} 100$ for sham, one week and three weeks group of lung sections respectively after intratracheal saline or BLM administration to male balb/c mice. 


\subsection{Biochemical indices of lung injury}

Serum activity of ALP, GGT, LDH, CK and AST with Uric acid concentration exhibited an increase as early as one week after surgery compared to sham group, which remained increased after three weeks in serum uric acid concentration, ALP, GGT and LDH activity. A nonsignificant change of serum CK and AST activity was observed after three weeks compared with sham group.
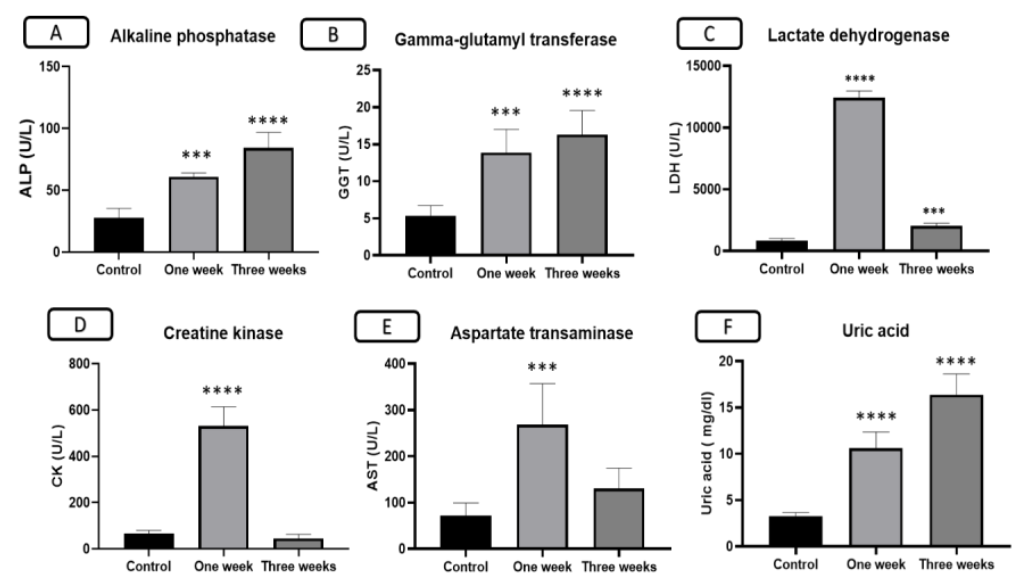

Figure 2: Effect of BLM-induced lung fibrosis in mice model on pathophysiological markers in serum as ALP activity (A), GGT activity (B), LDH activity (C), CK activity (D), AST activity (E) and Uric acid concentration (F) compared with normal control group. Data are expressed as mean \pm SEM $(n=5 ; * * * p<0.001 ; * * * * p<0.0001)$ compared to control group.

\subsection{Lung mRNA expression of TLR4, NF-kB, IL1B and TGF- $\beta$}

TGF- $\beta 1$ mRNA expression was overexpressed in BLM-induced lung fibrosis mice when compared with that in normal mice. In addition, BLM instillation significantly upregulated the mRNA expression of the key receptor to induce a proinflammatory response which called TLR4 leading to translocation of a fundamental cellular mediator NF-kB which is activated by a variety of extracellular stimuli including IL1B.
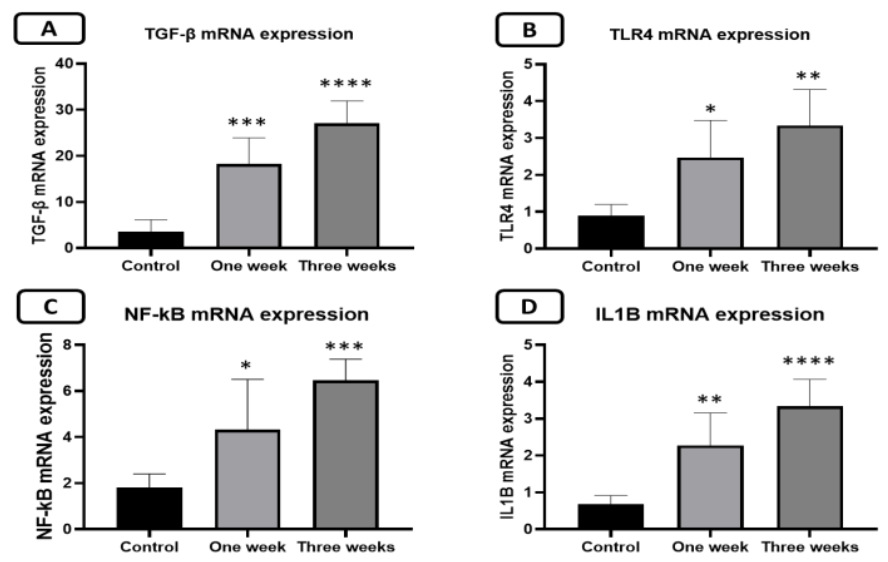

Figure 3: Effect of BLM on mRNA expression of TLR4, TGF- $\beta$, NF-kB and IL1B in mice lung tissues in different groups which normalized to mRNA of GAPDH; (A) Expression of TGF- $\beta$ mRNA in lung tissue. (B) Expression of TLR4 mRNA in lung 
tissue in different groups. (C) Expression of NF-kB mRNA in lung tissue in different groups. (D) Expression of IL1B mRNA in lung tissue in different groups. Data are expressed as mean \pm SEM $(\mathrm{n}=5 ; * \mathrm{p}<0.05 * * \mathrm{p}<0.01 ; * * * \mathrm{p}<0.001 ; * * * * \mathrm{p}<0.0001)$ compared to control group.

\section{Discussion}

IPF is a specific form of chronic progressive fibrosing ILD of unknown cause. A chronic inflammatory process of the lung has long been considered the main mechanism underlying IPF. However, there has been a conception in IPF pathogenesis that fibrogenesis inflammatory driven process results from recurrent microinjury of alveolar epithelial cells followed by repair processes. (Balestro et al., 2016).

BLM model is the most extensively used animal model due to its ability to reproduce many aspects of IPF and other fibrotic ILDs, good reproducibility, and ease of induction. Previous studies used the BLM model to identify many of the cellular and molecular mechanisms involved in the pathogenesis of IPF and other fibrotic ILDs, as well as novel therapies for these diseases, including two recent drugs approved for treatment of IPF(Liu et al., 2017c).

In the present study, we investigated the expression pattern of different inflammatory and fibrotic molecules which may affect fibrosis developments due to BLM. Our results revealed that progressive interstitial fibrosis and inflammation were increased as the time increased.

Lung samples that analyzed for collagen fibers accumulation demonstrated the progression of fibrosis and collagen fibers accumulation. Three weeks of BLM instillation resulted in a significant increase in proliferative collagenic bundles around bronchioles and the alveoli indicating an excessive fibrotic lung damage.

In fact, tissue damage and inflammation are important triggers for regeneration and fibrosis. Tissue damage not only induces inflammation in general, it also determines the type and polarization of inflammation by recruiting and activating a variety of different cells types of the innate and adaptive immune system(Liu et al., 2017c).

In our study, elevated LDH and ALP in lung tissue of BLM-induced lung fibrosis mice model are consistent with that of lung tissue isolated from patients with IPF. In addition, in vitro overexpression of LDH in primary human lung fibroblasts induces activation of TGF- $\beta 1$ and myofibroblast differentiation(Judge et al., 2018).

Furthermore, the increased uric acid level in all grades of model accompanied by IL1B production. Therefore, BLM-induced lung inflammation and remodeling are largely mediated by uric acid, which represents a major danger signal likely released from dying pulmonary cells upon injury and a new target to control inflammation upon lung(Gasse et al., 2009).

GGT is an enzyme present in serum and on the outer surface of cells from different organs such as the liver, pancreas, intestine, lungs and kidneys. Serum GGT is not only a traditional marker of alcohol consumption and hepatobiliary diseases, but 
several studies have also shown an association between elevated serum GGT levels and cardiovascular disease, diabetes mellitus, hypertension and metabolic syndrome. GGT levels is a predictor of mortality in the general population; in fact, this enzyme has recently been included as one of a set of biochemical parameters that predict mortality. Furthermore, serum GGT levels could help to interpret high ALP values of unclear origin(Caravaca-Fontán et al., 2017). Our findings support a crucial role of GGT which is the enzyme responsible for the hydrolysis of extracellular reduced glutathione (GSH), one of the main intracellular antioxidants in mammals, enabling the precursor amino acids to be subsequently used for new intracellular GSH synthesis. We found that, increased GGT which is an expression of intracellular GSH depletion and, therefore, GGT could be considered as a marker of oxidative stress(Bulusu et al., 2016).

Elevated CK activity in our model supported the previous studies that exhibited the association of collagen vascular disease with elevated CK in IPF patients (Mittoo et al., 2009). CK plays a key role in the energy metabolism of smooth muscle and nonmuscle tissues and cells(Fireman et al., 2001). CK catalyzes the reversible phosphotransfer between the ATP/ADP and Creatine/Phosphocreatine systems which BB-CK is a widely distributed type in smooth muscle (Teixeira et al., 2012).

TLRs play a fundamental role in the innate immune response and respond to conserved microbial products and endogenous molecules resulting from cellular damage to elicit an effective defense against invading pathogens, tissue injury, or cancer(Li et al., 2019). TLRs are expressed in a variety of cells, including type II alveolar epithelial cells, airway epithelial, smooth muscle cells, and fibroblasts (Ahmed et al., 2016).

Recent studies suggest that TLR4 is the key mediator in the onset of IPF (Hanson et al., 2019). Our studies exhibited that the TLR-mediated activation of innate immune cells leads to the production of pro-inflammatory factor NF-Kappa B, which is a major transcription factor that regulates various cell processes such as embryonic immunity, apoptosis, angiogenesis, development and proliferation.

On the other hand, we found that NF-Kappa B is necessary for the gene expression of many inflammatory mediators, such as IL1B which is consistent with the previous studies (Tang et al., 2018). TLR4 is a key regulator of the pro-inflammatory transcription NF- $\kappa \mathrm{B}$ and plays a dominant role in mediating sterile tissue damage(Ahmed et al., 2016).

In addition, we found that the activation of TLR4 signaling in explanted fibroblasts resulted in enhanced collagen synthesis and increased expression of multiple genes involved in tissue remodeling and extracellular matrix homeostasis. Also, TLR4 dramatically enhanced the sensitivity of fibroblasts to the stimulatory effect of TGF- $\beta 1$ as (Bhattacharyya et al., 2013).

The enhanced expression of TGF- $\beta$ as a fibrotic molecule and potent profibrogenic cytokine from one week group to reach its maximum in the late stage three weeks group encouraged lung fibroblasts to secrete collagens or induce 
transformation of fibroblasts to myofibroblasts that express $\alpha$-smooth muscle actin ( $\alpha$ SMA). Both are crucial steps in the pathogenesis of lung fibrosis(Raish et al., 2018).

Finally, the elevated TLR4 and NF- $\kappa \mathrm{B}$ expression in fibrotic lung tissues strongly supports a role for TLR4/NF- $\kappa \mathrm{B}$ pathway in mediating pulmonary fibrosis.

\section{Conclusion}

In conclusion, we found a strong association of TLR4, NF- $\kappa B$, TGF- $\beta$ and IL1B expression with the development and severity of lung fibrosis in BLM -induced pulmonary fibrosis. our findings also exhibiting the importance of TLR4/NF-kB as significant mediators in fibrotic lung injury and open the door for future therapy that can improve the lifestyle of IPF patients.

\section{Financial Disclosure}

This research did not receive any specific grant from funding agencies in the public, commercial, or not-for-profit sectors.

\section{Declaration of Interest Section}

The authors report no declarations of interest.

\section{REFERENCES}

Ahmed, S., Moawad, M., Elhefny, R., \& Abdullatif, M. 2016. Is toll like receptor 4 a common pathway hypothesis for development of lung cancer and idiopathic pulmonary fibrosis? Egyptian Journal of Chest Diseases and Tuberculosis, 65(1): 289-294.

Balestro, E., Calabrese, F., Turato, G., Lunardi, F., Bazzan, E., Marulli, G., Biondini, D., Rossi, E., Sanduzzi, A., Rea, F., Rigobello, C., Gregori, D., Baraldo, S., Spagnolo, P., Cosio, M. G., \& Saetta, M. 2016. Immune Inflammation and Disease Progression in Idiopathic Pulmonary Fibrosis. PLoS One, 11(5): e0154516.

Bhattacharyya, S., Kelley, K., Melichian, D. S., Tamaki, Z., Fang, F., Su, Y., Feng, G., Pope, R. M., Budinger, G. R., Mutlu, G. M., Lafyatis, R., Radstake, T., Feghali-Bostwick, C., \& Varga, J. 2013. Toll-like receptor 4 signaling augments transforming growth factor- $\beta$ responses: a novel mechanism for maintaining and amplifying fibrosis in scleroderma. Am J Pathol, 182(1): 192205.

Bulusu, S., \& Sharma, M. 2016. What does serum gamma-glutamyltransferase tell us as a cardiometabolic risk marker? Ann Clin Biochem, 53(Pt 3): 312-332.

Caravaca-Fontán, F., Azevedo, L., Bayo, M. Á., Gonzales-Candia, B., Luna, E., \& Caravaca, F. 2017. High levels of both serum gamma-glutamyl transferase and alkaline phosphatase are independent predictors of mortality in patients with stage 4-5 chronic kidney disease. Nefrología (English Edition), 37(3): 267-275. 
El-Zayat, S. R., Sibaii, H., \& Mannaa, F. A. 2019. Toll-like receptors activation, signaling, and targeting: an overview. Bulletin of the National Research Centre, 43(1): 187.

Fireman, E., Shahar, I., Shoval, S., Messer, G., Dvash, S., \& Grief, J. 2001. Morphological and Biochemical Properties of Alveolar Fibroblasts in Interstitial Lung Diseases. Lung, 179(2): 105-117.

Gasse, P., Riteau, N., Charron, S., Girre, S., Fick, L., Petrilli, V., Tschopp, J., Lagente, V., Quesniaux, V. F., Ryffel, B., \& Couillin, I. 2009. Uric acid is a danger signal activating NALP3 inflammasome in lung injury inflammation and fibrosis. Am J Respir Crit Care Med, 179(10): 903-913.

Ge, J., Tang, L., Mu, P., Zhu, F., Xie, L., \& Tang, Y. 2020. Association of ADAM17 Expression Levels in Patients with Interstitial Lung Disease. Immunol Invest, 49(1-2): 134-145.

Hanson, K. M., Hernady, E. B., Reed, C. K., Johnston, C. J., Groves, A. M., \& Finkelstein, J. N. 2019. Apoptosis Resistance in Fibroblasts Precedes Progressive Scarring in Pulmonary Fibrosis and Is Partially Mediated by TollLike Receptor 4 Activation. Toxicological Sciences, 170(2): 489-498.

Jiang, D., \& Liang, J. 2019. A Long Noncoding RNA links TGF- $\beta$ Signaling in Lung Fibrosis. 200(2): 123-125.

Judge, J. L., \& Nagel, D. J. 2018. Prevention and treatment of bleomycin-induced pulmonary fibrosis with the lactate dehydrogenase inhibitor gossypol. 13(5): e0197936.

Kolb, M., \& Vašáková, M. 2019. The natural history of progressive fibrosing interstitial lung diseases. Respiratory Research, 20(1): 57.

Li, Y., \& Deng, S. L. 2019. Roles of Toll-Like Receptors in Nitroxidative Stress in Mammals. 8(6).

Liu, M. H., Lin, A. H., Ko, H. K., Perng, D. W., Lee, T. S., \& Kou, Y. R. 2017 a. Prevention of Bleomycin-Induced Pulmonary Inflammation and Fibrosis in Mice by Paeonol. Front Physiol, 8: 193.

Liu, T., De Los Santos, F. G., \& Phan, S. H. 2017b. The Bleomycin Model of Pulmonary Fibrosis. Methods Mol Biol, 1627: 27-42.

Liu, T., De Los Santos, F. G., \& Phan, S. H. 2017c. The bleomycin model of pulmonary fibrosis, Fibrosis: 27-42: Springer.

Luo, M., Yan, D., Sun, Q., Tao, J., Xu, L., Sun, H., \& Zhao, H. 2019. Ginsenoside $\operatorname{Rg} 1$ attenuates cardiomyocyte apoptosis and inflammation via the TLR4/NFkB/NLRP3 pathway. J Cell Biochem. 
Mack, M. 2018. Inflammation and fibrosis. Matrix Biol, 68-69: 106-121.

Mitsui, K., Ikedo, T., Kamio, Y., Furukawa, H., Lawton, M. T., \& Hashimoto, T. 2020. TLR4 (Toll-Like Receptor 4) Mediates the Development of Intracranial Aneurysm Rupture. Hypertension: HYPERTENSIONAHA. 118.12595.

Mittoo, S., Gelber, A. C., Christopher-Stine, L., Horton, M. R., Lechtzin, N., \& Danoff, S. K. 2009. Ascertainment of collagen vascular disease in patients presenting with interstitial lung disease. Respiratory medicine, 103(8): 11521158.

Mulero, M. C., Wang, V. Y., Huxford, T., \& Ghosh, G. 2019. Genome reading by the NF- $\kappa B$ transcription factors. Nucleic Acids Res, 47(19): 9967-9989.

Page, D. L. 1983. Theory and practice of histological techniques. Human Pathology, 14(10): 925-926.

Raish, M., Ahmad, A., Ansari, M. A., Ahad, A., Al-Jenoobi, F. I., Al-Mohizea, A. M., Khan, A., \& Ali, N. 2018. Sinapic acid ameliorates bleomycin-induced lung fibrosis in rats. Biomedicine \& Pharmacotherapy, 108: 224-231.

Reed, E. B., Ard, S., La, J., Park, C. Y., Culligan, L., Fredberg, J. J., Smolyaninova, L. V., Orlov, S. N., Chen, B., Guzy, R., Mutlu, G. M., \& Dulin, N. O. 2019. Anti-fibrotic effects of tannic acid through regulation of a sustained TGF-beta receptor signaling. Respiratory Research, 20(1): 168.

Seki, E., De Minicis, S., Österreicher, C. H., Kluwe, J., Osawa, Y., Brenner, D. A., \& Schwabe, R. F. 2007. TLR4 enhances TGF- $\beta$ signaling and hepatic fibrosis. Nature Medicine, 13(11): 1324-1332.

Tang, R., Lin, Y.-M., Liu, H.-X., \& Wang, E.-S. 2018. Neuroprotective effect of docosahexaenoic acid in rat traumatic brain injury model via regulation of TLR4/NF-Kappa B signaling pathway. The international journal of biochemistry \& cell biology, 99: 64-71.

Tashiro, J., Rubio, G. A., Limper, A. H., Williams, K., Elliot, S. J., Ninou, I., Aidinis, V., Tzouvelekis, A., \& Glassberg, M. K. 2017. Exploring Animal Models That Resemble Idiopathic Pulmonary Fibrosis. Frontiers in Medicine, 4(118).

Teixeira, A. M., \& Borges, G. F. 2012. Creatine kinase: structure and function. Brazilian Journal of Biomotricity, 6(2): 53-65.

Wei, P., Xie, Y., Abel, P. W., Huang, Y., Ma, Q., Li, L., Hao, J., Wolff, D. W., Wei, T., \& Tu, Y. 2019. Transforming growth factor (TGF)- $\beta 1$-induced miR-133a inhibits myofibroblast differentiation and pulmonary fibrosis. Cell Death \& Disease, 10(9): 670. 


\section{مسار الإثارة للمستقبل الثبيه بالتول ؛ هو الحدث الرئيسي الممرض لإصابة الرئة في التليف الرئوي الناجم عن بلوميسين التوني التوني}

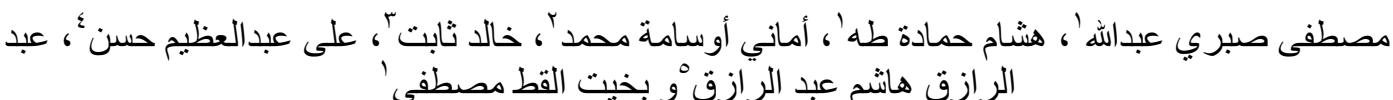

$$
\begin{aligned}
& \text { 'قسم الكيمياء الحيويةـ كلية الصيدلة ـ جامعة الأزهر فرع أسيوط - أسيوط - جمهورية مصر العربية. } \\
& \text { كقمم الكيمياء الحيوية _ كلية الطب - جامعة أسيوط ـ أسيوط - جمهورية مصر العربية. } \\
& \text { "َقم الكيمياء الحيوية ـ كلية الصبيلة - جامعة المنيا ـ المنيا - جمهورية مصر العربية. } \\
& \text { قُم الأمر اض الصدرية_ كلية الطب - جامعة أسيوط ـ أسيوط - جمهورية مصر العربية. } \\
& \text { ققم الهستولوجى - كلية الطب البيطرى - جامعة بنى سويف - بنى سويف - جمهورية مصر العربي. } \\
& \text { المؤلف المسئول: mostafagaballah@azhar.edu.eg }
\end{aligned}
$$

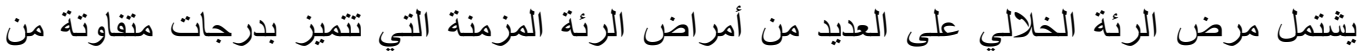

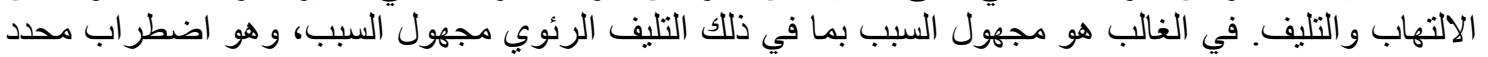

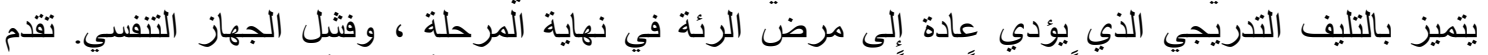

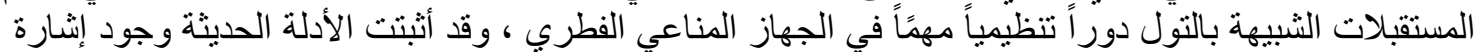

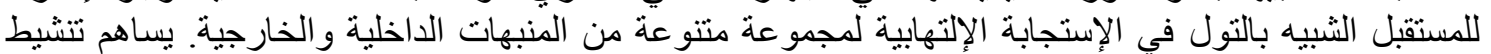

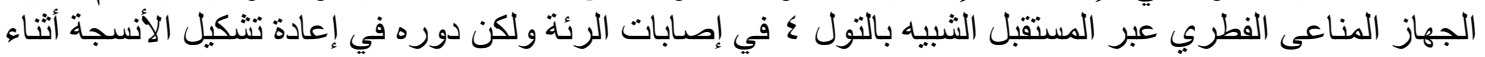

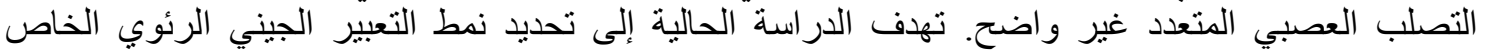

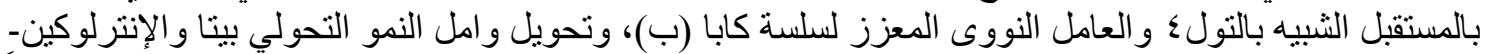

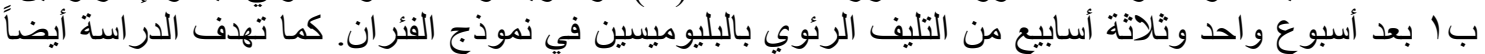

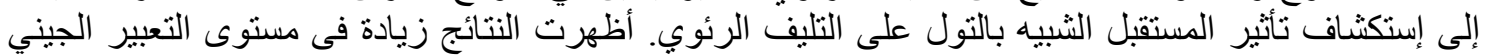

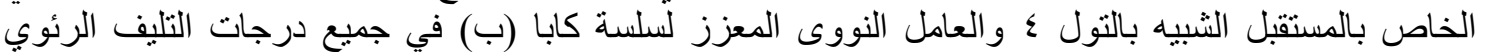

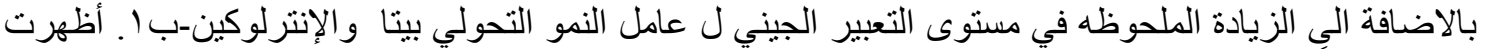

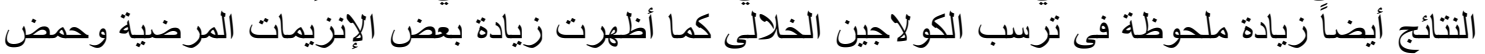

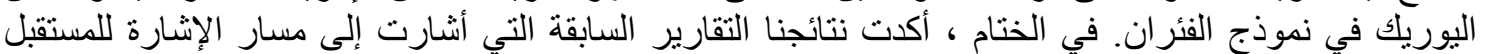

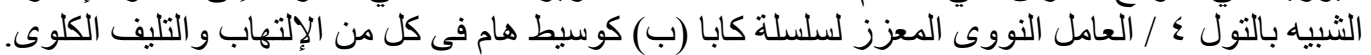

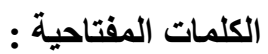

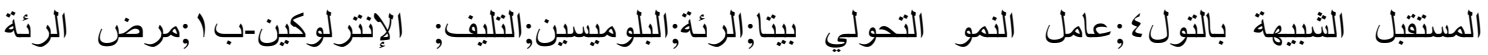

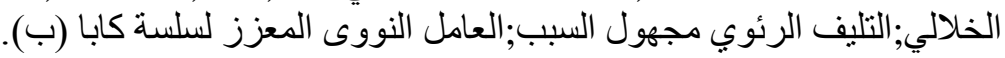

